\title{
Intestinal Eosinophilic: Anisakiasis
}

\author{
Jose Aneiros-Fernandez ${ }^{\mathrm{a}, \mathrm{b}}$, Mercedes Caba Molina ${ }^{\mathrm{a}}$, Rosa Rios Pelegrina ${ }^{\mathrm{a}}$, Alina Nicolae, \\ Ovidiu Preda ${ }^{a}$, Francisco O’Valle ${ }^{a}$, Jose Aneiros Cachaza ${ }^{a}$, Miguel Camara Pulido ${ }^{a}$
}

\begin{abstract}
Anisakiasis is a parasitic disease in which the human is an accidental host, due to the intake of raw or lightly cooked fish or squid that is infected by the larvae dematodes, family Anisakidae. We describe a case in a 51-year-old woman with parasitic infection Anisakiasis, which affects the large intestine.
\end{abstract}

Keywords: Anisakiasis; Intestinal; Abdominal pain

\section{Introduction}

Anisakiasis is a parasitic disease in which the human is an accidental host, due to the intake of raw or lightly cooked fish or squid that is infected by the larvae dematodes, family Anisakidae (Anisakis simplex, Anisakis physeteris, Pseudoterranova decipiens) [1-5]. The clinical manifestations are varied, which can be asymptomatic patients with gastrointestinal symptoms or allergic type [6-9]. There has been an increase in this disease, due to the widespread exchange of food cultures around the world, such as eating raw fish (sushi and sashimi) [5]. We report a case of parasitic infection Anisakiasis, which affects the large intestine.

\section{Case Report}

A woman of 51 years of age attended the emergency department for acute abdominal pain localized in right iliac fossa. The personal background of the patient includes gallstones

\footnotetext{
Manuscript accepted for publication August 24, 2010

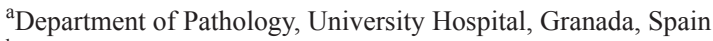

${ }^{\mathrm{b}}$ Corresponding author: Department of Pathology, University Hospital, Granada, Avd. Madrid S/N. CP: 18012, Spain.

Email: janeirosf@hotmail.com
}

doi:10.4021/jmc51e and cholelithiasis. The patient has a family history of colon cancer (two brothers). At physical examination the patient had good general condition, no fever without spontaneous pain. On palpation, she showed a globular abdomen at the level of right upper quadrant, with tenderness in the right iliac fossa. Blumberg's sign was negative. Laboratory tests showed 12,000 leukocytes without neutrophilia or eosinophilia. The other values were normal. Radiological techniques demonstrated a thickening of the right bowel wall without occluding the light with ascitic fluid. With suspicion of intestinal cancer in the right colon, colonoscopy was performed, which demonstrated no tumor process that emerges from the intestinal mucosa. Since the patient remained in severe pain, along with clinical suspicion and family history of bowel cancer, right hemicolectomy with ileocolic anastomosis was performed. The macroscopic study and the opening of the surgical specimen showed an increase in thickness of the wall. We show the level of the mucosa in an area slightly eroded, with the presence of an elongated structure, $1 \mathrm{~cm}$ in length, which penetrated the mucosa intestinal (we suggested a parasite) (Fig. 1). Histological study of intestinal thickening showed a slightly eroded mucosa, edema at the level of the submucosa with vascular congestion. At the level of deep and superficial muscle layer, an intense acute inflammatory infiltrate with abundant eosinophils was identified. At the level of blood extravasation, there was serous meso-

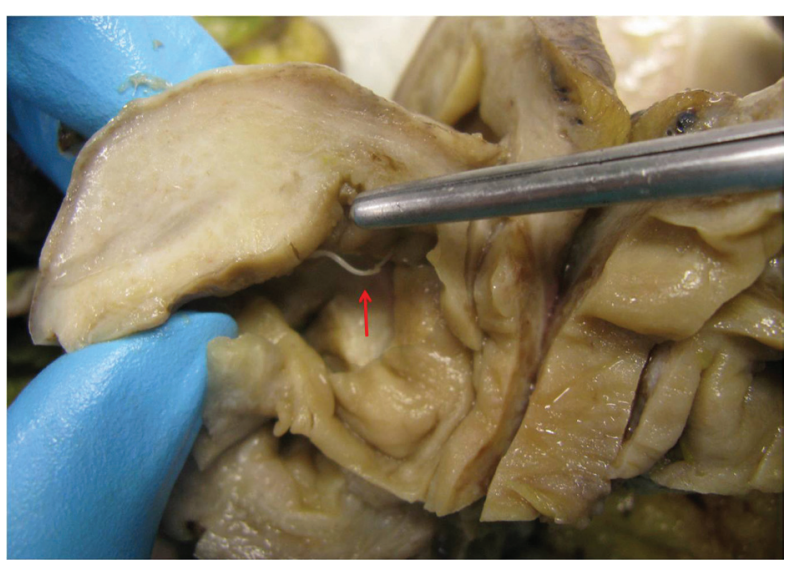

Figure 1. Showed parasite that perforating the bowel mucosa. 


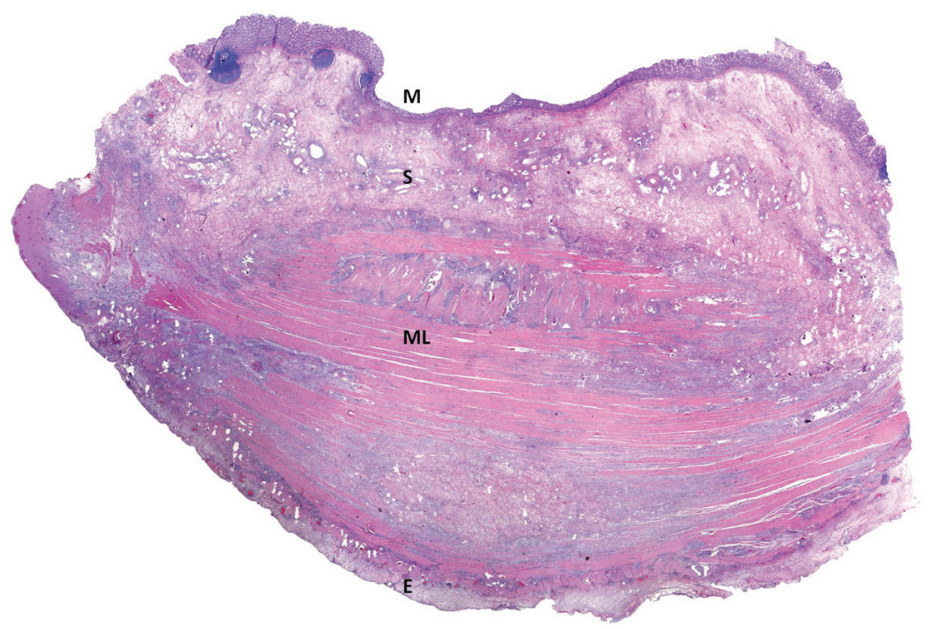

Figure 2. Panoramic histology of the intestinal wall: show mucosa with little erosion (M), edematous submucosa (S), muscle layer with intense inflammatory infiltrate $(\mathrm{ML})$ and the serosa with edema and inflammatory infiltration (E) (hematoxiline and eosine).

thelial hyperplasia (Fig. 2). Histological examination of the filamentary structure corresponded with a parasitic nematode, showing a thick cuticle, neural cord, and gastrointestinal structure (Fig. 3). With all these findings the diagnosis was made of Anisakiasis of the colon. No evidence of malignant tumor process was seen. The patient reported taking fish in the last month. The patient did not show alterations in relation to infection after 6 months.

\section{Discussion}

The species of Anisakis has a complex life cycle: the eggs hatch in seawater, and shellfish feed on the larvae. These crustaceans are eaten by a fish or cephalopods such as octopus or squid, staying the nematode in the gut wall, into the

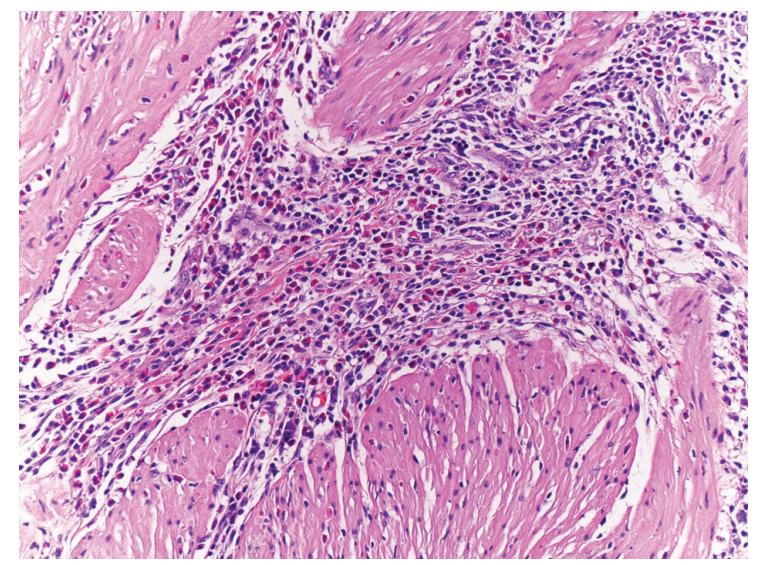

Figure 3. Presenting an intense inflammatory infiltrate with eosinophils (magnification $\times 40$, Hematoxiline and Eosine). muscle or under the skin. Humans become infected by eating raw or undercooked fish [1-8]. Three species of Anisakis larvae are pathogenic to humans: Anisakis simplex, Pseudoterranova decipiens, and Contracaecum. The areas with the highest incidence of cases caused by Anisakis are Japan, Netherlands and South America, although in recent years there has been a surge in non-endemic countries caused by an exchange of food cultures [7].

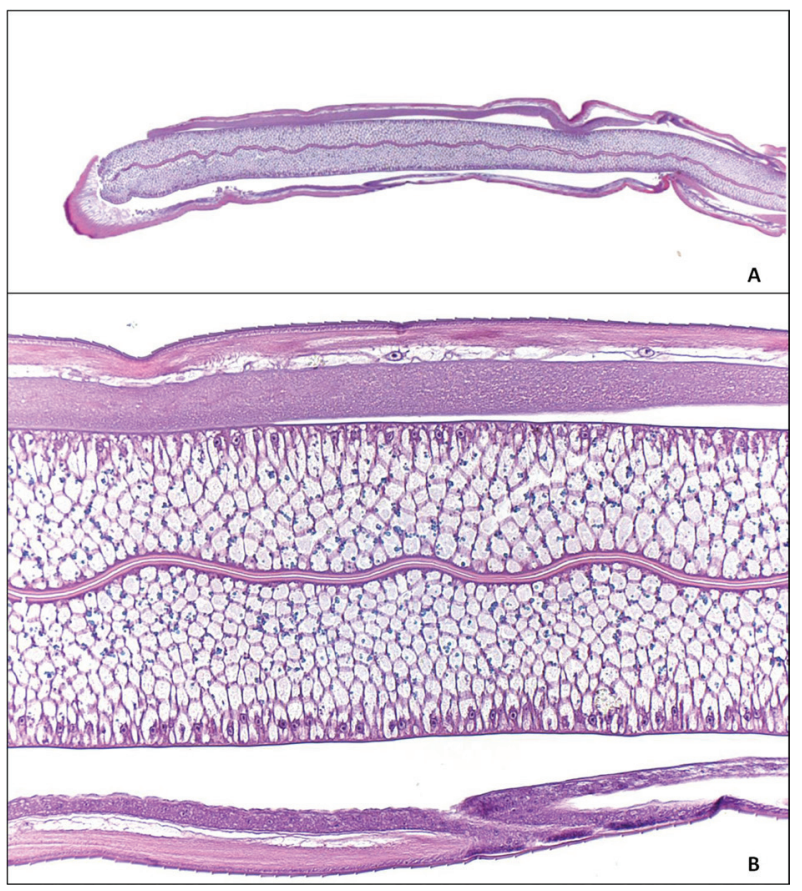

Figure 4. Histological examination of the parasitic nematode, showing a thick cuticle, neural cord, and gastrointestinal structure $(A, B)$ (hematoxiline and eosine). 
The highly variable clinical manifestations, digestive disorders are more common as right iliac fossa pain, obstruction, abdominal pain, vomiting, epigastric pain and bleeding. They may also have allergic skin reactions in the form of generalized papular erythema. These symptoms are caused by local action of the parasite causing gastrointestinal disturbances and hypersensitivity reactions mediated by $\operatorname{IgE}$ [10-12]. According to laboratory values, the eosinophilia is not usually present in the gastric or intestinal Anisakiasis as showing in most cases, and leukocytosis is not usually present in the intestinal involvement as in our case. Serological diagnosis and skin testing are important in acute and chronic cases. Elisa Western Blott, monoclonal antibodies, eosinophilic cationic protein and $\operatorname{IgE}$ determination to Anis 1 are used.

The differential diagnosis should be performed with numerous processes such as eosinophilic enteritis, appendicitis, diverticulitis, Crohn's disease, ischemia, tuberculosis and malignancies [13].

There are studies to control the growth of the disease and control mechanisms and prevention. It was found that before taking fish kept at -20 degrees for 24 hours or 60 degrees for 10 minutes the larva is not viable. Treatment of Anisakiasis is the administration of anthelmintics for $1-2$ weeks [10].

We think that with a good clinical history detailed in food intake after a good box accompanied, abdominal radiologic and endoscopic study is crucial for the diagnosis of Anisakiasis. In our case, due to family history of colon cancer and clinical-radiologic suspicion, surgery was performed.

\section{Conflict of Interests}

The authors have no conflict of interest to declare. All authors have participated sufficiently to take public responsibility for appropriate portions of the work. There are no founding sources.

\section{References}

1. Couture C, Measures L, Gagnon J, Desbiens C. Human intestinal anisakiosis due to consumption of raw salmon. Am J Surg Pathol 2003;27(8):1167-1172.

2. Miura T, Iwaya A, Shimizu T, Tsuchiya J, Nakamura J, Yamada S, Yanagi M, et al. Intestinal anisakiasis can cause intussusception in adults: an extremely rare condition. World J Gastroenterol 2010;16(14):1804-1807.

3. Martinez Caselles A, Sanchez Torres A, Egea Valenzuela J, Carballo Alvarez F. [Bowel subocclusion by Anisakis]. Rev Esp Enferm Dig 2009;101(11):818-819.

4. Nakaji K. Enteric anisakiasis which improved with conservative treatment. Intern Med 2009;48(7):573.

5. Takei H, Powell SZ. Intestinal anisakidosis (anisakiosis). Ann Diagn Pathol 2007;11(5):350-352.

6. Matsuo S, Azuma T, Susumu S, Yamaguchi S, Obata S, Hayashi T. Small bowel anisakiosis: a report of two cases. World J Gastroenterol 2006;12(25):4106-4108.

7. Navarro Cantarero E, Carro Alonso B, Castillo Lario C, Fernandez Gomez JA. [Diagnosis of Anisakis infestation: experience in our environment]. Allergol Immunopathol (Madr) 2005;33(1):27-30.

8. Arlian LG, Morgan MS, Quirce S, Maranon F, Fernandez-Caldas E. Characterization of allergens of Anisakis simplex. Allergy 2003;58(12):1299-1303.

9. Sasaki T, Fukumori D, Matsumoto H, Ohmori H, Yamamoto F. Small bowel obstruction caused by anisakiasis of the small intestine: report of a case. Surg Today 2003;33(2):123-125.

10. Schuster R, Petrini JL, Choi R. Anisakiasis of the colon presenting as bowel obstruction. Am Surg 2003;69(4):350-352.

11. Perez-Naranjo S, Venturini-Diaz M, Colas-Sanz C, Aguilella-Diago V, Ruiz-de-la-Iglesia F, Perez-Calvo JI. Intestinal anisakiasis mimicking intestinal obstruction. Eur J Med Res 2003;8(3):135-136.

12. Caballero ML, Moneo I. Specific IgE determination to Ani s 1, a major allergen from Anisakis simplex, is a useful tool for diagnosis. Ann Allergy Asthma Immunol 2002;89(1):74-77.

13. Torre I, Gutierrez-Macias A, Elorriaga K, Martin E, Zubero Z, Santamaria JM. [Intestinal occlusion in a previously healthy woman]. Enferm Infecc Microbiol Clin 2002;20(10):531-532. 